\section{Praszerosa confu-}

de fronteiras:

spobre • imaginá-

\section{do excesso e da transgressão}

\section{RESUMO}

Este artigo examina as noções de excesso e transgressão nos discursos da cibercultura. Defende-se a hipótese de que a retórica libertária e revolucionária dos ciberutopismos oculta, na realidade, uma cosmovisão essencialmente conservadora e marcada pelos mitos da modernização progressiva.

\section{ABSTRACT}

This paper discusses the notions of excess and trans-gression propagated by cyberculture's discourses and find them to be very conservative and modernist.

\section{palaVRAS-chaVe (Key WORDS) \\ - Cibercultura (Cyberculture) \\ - Transgressão (Transgression) \\ - Excesso (Excess)}

\author{
"There is pleasure sure, in being mad, \\ which none but madmen know" \\ John Dryden, The Spanish Friar \\ “When reality just isn't good enough, \\ pleasure must be synthesized" \\ Iara Lee, Synthetic Pleasures
}

A FRASE QUE anuncia o excelente documentário de Iara Lee, Synthetic Pleasures, é sintomática de uma situação cultural dominada pelo tema do excesso. É preciso ir além, ultrapassar todos os limites, viver todas as experiências e criar ainda outras novas. Como diz Omar Calabrese, nossa era neobarroca tem como um de seus traços identificadores básicos o desejo do rompimento dos limites, do atravessamento das fronteiras. "Desmesura e excedência estão entre as principais constantes formais dos contentores neobarrocos, sobretudo no âmbito da civilização de massas" (1988: 77). A noção de excesso aparece, de fato, em todos os campos da vida cultural, mas com força redobrada no horizonte dos meios de comunicação massivos. O cinema hollywoodiano é, talvez, a maior demonstração desse prazer excêntrico. Filmes como Matrix (1999) ou Star Wars: Attack of the Clones (2002), com suas explosões monumentais e incríveis efeitos especiais, representam com perfeição essa categoria estética que poderíamos denominar como um gosto pelo excessivo.

O prazer pela ruptura, que se desdobra em diversas formas, manifesta-se também nitidamente no campo daquilo que se convencionou chamar cibercultura. Os discursos sobre as novas tecnologias de informação e comunicação, como indica o bordão de Synthetic Pleasures, repetem incessantemente a idéia de que é preciso avançar todos os sinais, derrubar todas as barreiras, inclusive aquelas que tradicionalmente definiam categorias ontológicas, como a separação humano-inumano. Retomando a reflexão de Bataille sobre a noção de despesa, André Lemos detecta, com perspicácia, esse traço fundamental da cibercultura: 
A cibercultura fornece vários exemplos de uma despesa excessiva, não acumulativa e irracional de bits. Dançar por horas em festas tecno, viajar por vínculos banais e efêmeros do ciberespaço, produzir vírus, penetrar sistemas de computador, trocar informação frívola em bate-papos e grupos temáticos, etc. (2002: 264)

Mas o que uma abordagem crítica pode nos revelar a respeito desse tropo? Onde poderíamos encontrar suas origens? Qual é a extensão integral das idéias envolvidas nesse tema e de que visão de mundo ela constitui uma expressão? Este artigo é uma tentativa de formular algumas respostas iniciais. Para tanto, convém tecer algumas considerações sobre as noções de equilíbrio e excesso, pois compreender o papel que desempenham no horizonte da tecnocultura contemporânea exige antes a obtenção de uma clareza mínima a respeito dos sentidos que podemos atribuir-lhes. Pretendo abordar essas noções a partir de perspectivas físicas (ou "físico-filosóficas") e antropológicas, já que é nos âmbitos da ciência, da filosofia e da cultura que se desenham (e por vezes se cruzam) os temas do equilíbrio e do excesso.

Do ponto de vista da física clássica, a tendência natural do universo pode ser caracterizada como um processo de entropia. Dado um sistema fechado (que é provavelmente o caso do universo), a energia inicialmente ali manifestada tende a se dissipar com o tempo. Sabemos que o que permite a manutenção de qualquer sistema é um estado de heterogeneidade, no qual as várias forças envolvidas se diferenciam continuamente. Em qualquer sistema fechado, parte-se de um estado inicial de diferenciação onde a energia sofre diversas transformações e vai se degradando progressivamente. Com o passar do tempo, a energia se perde em formas não aproveitáveis, como, por exemplo, calor. Pode-se dizer, portanto, que a morte de todo sistema é representada pela passagem da heterogeneidade à homogeneidade.

Essa situação, contudo, se complexifica no âmbito da física contemporânea. A percepção de que determinados fenômenos microfísicos podem ser entendidos como energia ou matéria (caso dos fótons, por exemplo) oferece novas perspectivas para pensar as questões do equilíbrio, da heterogeneização e da homogeneização.

Stéphane Lupasco, por exemplo, argumenta que ambos os processos são necessários para o funcionamento dos sistemas microfísicos. Nessa relação entre diferença e indiferenciação, na qual operaria uma lógica paradoxal, homogeneização e heterogeneização estão presentes simultaneamente, em estados diferenciados de virtualidade ou atualidade. Em outras palavras, para que um sistema se homogeneíze, é necessário que as formas de homogeneização estejam presentes desde sempre, em estado de virtualidade ou potência, para então progressivamente se atualizarem dentro do sistema. Da mesma maneira, para que possa haver heterogeneização no sistema, as forças de heterogeneidade devem estar continuamente presentes, ainda que na forma de potencialidade. Como diz Lupasco, "cada evento energético, cada processo dinâmico passa de um certo estado de potencialidade a um certo estado de atualização. Mas ele pode apenas fazê-lo potencializando o evento energético antagonista que o mantém como tal através de seu estado de atualização" (1970: 36).

Lupasco observa, assim, que é possível falar em dois tipos de matéria: a macrofísica - mundo das nossas experiências cotidianas -, na qual os processos de homogeneização são dominantes e a levam a um estado de não-contradição e estabilidade máximas, e a microfísica, na qual se manifesta uma orientação inversa, em direção ao antagonismo simétrico e contraditório. Mas é possível falar ainda em um terceiro tipo de matéria, segundo Lupasco, a matéria viva. O interessante na organização dos sistemas vivos é que eles se constituem numa forma 
de matéria que luta constantemente contra o segundo princípio da termodinâmica (a entropia, a morte). Trata-se de um sistema voltado especificamente para os dinamismos heterogeneizantes. Ainda que submetida às leis do mundo macrofísico, à tendência ao equilíbrio e estabilidade, a matéria viva resiste, se diversifica e se desdobra em sistemas de complexidade crescente.

Todo esse belo (e em grande parte incompreensível para a maioria de nós, simples mortais) edifício científico não seria de grande ajuda se não fossem os postulados filosóficos derivados da argumentação. É possível sintetizar esses postulados em duas idéias fundamentais, importantes para o desenvolvimento da minha argumentação: 1) o universo tende à entropia; não há excesso de energia que possa ser desperdiçado. $\mathrm{O}$ que permite resistir à entropia, segundo Lupasco, são os mecanismos de equilíbrio dinâmico da matéria microfísica, 2) o verdadeiro equilíbrio, no plano do mundo microfísico (e da vida psíquica), consiste num regime de convivência antagonista entre forças de homogeneização e heterogeneização. A contradição absoluta ou a ausência total de contradição trariam a destruição do sistema (o excesso).

Do ponto de vista cultural, o tema da "despesa excessiva" é objeto de uma larga tradição de estudos antropológicos. $\mathrm{O}$ fenômeno do potlach, cuja descrição mais exaustiva encontra-se no célebre Essai sur le Don, de Marcel Mauss, consiste em uma cerimônia na qual o chefe de uma tribo oferece a um rival um presente, com vistas a humilhá-lo ou desafiá-lo. O rival deve, então, responder ao desafio, oferecendo, mais tarde, um novo potlach mais suntuoso e dispendioso que o primeiro. Mas observou-se também que a dádiva não era a única forma de manifestação do potlach. Por ocasiões, consistia na simples e espetacular destruição de imensas riquezas. Há casos em que o potlach envolve o assassínio de escravos, a queima de alimentos vitais ou até mesmo a destruição da própria aldeia.

Bataille irá retomar as reflexões da an- tropologia e desenvolver, sobre a noção do potlach, toda uma filosofia da despesa. Para Bataille, o fenômeno da dádiva remete ao desenvolvimento de uma economia geral, preocupada com o todo - ou seja, não apenas com a vida social, mas também com os fenômenos naturais. É na própria natureza - portanto, curiosamente, no horizonte de uma perspectiva física - que se funda o ato da dádiva. A natureza demonstra um excesso de energia, de vida (cujo maior exemplo é o sol). Esse excesso significa que a tendência da vida é expandir-se continuamente, e essa expansão é limitada apenas pelas dimensões da biosfera (Bataille, 1975: 67). As limitações imediatas do crescimento são dadas imediatamente, para cada indivíduo, através dos outros indivíduos. Daí a origem de fenômenos como o potlach: a energia em excesso precisa ser desperdiçada, sob pena de chegar a nos destruir. Nas sociedades capitalistas modernas, corre-se esse risco, já que seu princípio básico de funcionamento é a acumulação.

Nesta equação estão presentes dois componentes diversos que, porém, tendemos a confundir e tomar como um só: excesso e despesa (ou dispêndio). Na verdade, na tradição antropológica o tema do excesso não chega a se tornar o tópico central da discussão. Mauss e a tradição antropológica em geral encaravam a questão do potlach como uma expressão de poder por parte dos chefes tribais (o poder de dar e destruir), ou como um processo primitivo de troca sob forma ritual. É Bataille quem introduz decisivamente o tema do excesso, mas apenas para justificar sua teoria da dádiva. $\mathrm{O}$ excesso seria um fenômeno da natureza que se reflete no campo da vida cultural. O dispêndio inútil poderia, assim, ser encarado como um princípio de oposição ao conceito de utilidade do mundo capitalista.

$\mathrm{Na}$ verdade, quando falamos no tema sob uma perspectiva culturalista, pode-se entender que, na forma de acúmulo, o excesso chegue a ser considerado como essencialmente nefasto (Bataille). Por outro lado, se adotarmos a posição de Calabrese - que 
entende excesso como a ultrapassagem dos limites e formas tradicionalmente impostos por uma cultura - não existe propriamente um julgamento de valor. Na definição de Calabrese, "o excesso manifesta a ultrapassagem de um limite visto como caminho de saída de um sistema fechado" (1988: 63). Toda cultura se caracteriza por determinados limiares, confins, a partir dos quais qualquer fenômeno é considerado como rompimento de normas, como ação revolucionária. Mas Calabrese estabelece uma distinção importante entre limite e excesso. O limite significa operar nas fronteiras do sistema cultural sem de fato chegar a rompê-las, ao passo que o excesso implicaria a crise do sistema, exigindo uma total reformulação do mesmo. No caso da cultura contemporânea, Calabrese identifica um movimento complexo, entre limite e excesso, o que não permitiria classificar o neobarroco como época propriamente dinâmica ou "revolucionária". "O gosto neobarroco", afirma, "configura-se como perenemente em suspensão, excitado mas nem sempre disposto à subversão de categorias e valores" (1988: 80).

No domínio da cibercultura parece que lidamos precisamente com esse tipo de situação. Por um lado, encontramos discursos de entonação revolucionária que pregam a transgressão de normas e a ultrapassagem de todas as limitações políticas e sociais (ou mesmo biológicas); por outro, temos também os discursos que adotam uma posição conservadora, preocupada com os perigos do excesso, especialmente do excesso de informação. É relativamente fácil, porém, encontrar exemplos que oscilam entre esses dois pólos. No mission statement do Instituto Extropiano, dedicado ao desenvolvimento integral do homem em sua relação com a tecnologia, lemos que

\footnotetext{
"Avanços na tecnologia (incluindo as 'tecnologias sociais' da administração do conhecimento, aprendizagem e tomada de decisões) começam a nos capacitar para alterar a própria natu-
}

reza humana nos seus aspectos físicos, emocionais e intelectuais. As possibilidades radicais que agora emergem podem causar enormes problemas, assim como aperfeiçoar enormemente a condição humana/transhumana. Com melhores conhecimentos e processos de tomada de decisões, os humanos podem viver muito mais longamente numa saúde "mais que perfeita"; aprimorar seu autoconhecimento e consciência da dinâmica interpessoal; superar preconceitos culturais, psicológicos e meméticos na forma de pensar; aperfeiçoar a inteligência em todas as suas formas e aprender a desenvolver-se na mudança e evolução ${ }^{2 "}$.

Essa passagem nos oferece alguns elementos interessantes de análise. Em primeiro lugar, registre-se a presença da ambigüidade em relação à superação de limites possibilitada pela tecnologia. Esta pode "causar enormes problemas" ou promover extraordinários avanços. Trata-se de "possibilidades radicais", capazes, portanto, de conduzir a extremos opostos: a felicidade absoluta ou a desgraça total. Em segundo lugar, vemos o tema da saúde perfeita, ao qual Lucien Sfez dedica todo um livro. Sfez vê na idéia de saúde perfeita ou "grande saúde" a última grande ideologia possível da pós-modernidade. Mais que isso, afirma ele, trata-se de uma bio-eco-religião visando ao desenvolvimento de um super-homem que "liberto do dilaceramento vida/morte, dilaceramento constitutivo de nossa infeliz existência humana, atingiria a imortalidade e, desse modo, não precisaria mais de Deus, da moral e da metafísica" (1996: 21). Em terceiro lugar, intimamente vinculada ao tema da saúde total, evoca-se a mitologia do transhumanismo.

O transhumano é um ser que transcende as fronteiras da espécie, do gênero e até mesmo de seu reino, já que, de certo modo, pode resultar da combinação entre o animal e o mineral - por exemplo, das pastilhas de silício que, implantadas em seu corpo, 
ampliaram suas capacidades físicas e mentais. O tema do transhumano, assim como do pós-humano ou do ciborgue, repousa na idéia da superação dos limites impostos pelo estado natural. Como enuncia a já célebre frase cunhada por Donna Haraway em seu Manifesto Ciborgue, aqui lidamos com "o prazer da confusão de fronteiras” (2000: 42). Para Haraway, o ciborgue é criatura tanto do nosso imaginário como da nossa realidade cotidiana, que simboliza o rompimento, já em curso, das fronteiras tradicionalmente estabelecidas na cultura ocidental, como as de gênero (homem/mulher) ou natureza (orgânico/inorgânico).

Tiziana Terranova encara a filosofia do pós-humanismo como uma reelaboração contemporânea de um tema que já aparecia, ao menos embrionariamente, nos futuristas italianos ou em Nietzsche (com o que parece concordar Sfez). Todo o discurso transhumanista pode ser articulado em duas alternativas básicas: a extensão das capacidades do corpo ou a simples e pura ultrapassagem das limitações corporais (nas fantasias de digitalização da consciência). Terranova observa inteligentemente que as utopias transhumanistas são essencialmente individualistas e anti-sociais. No triunfo dessa vontade tecnológica, "a sociedade é apagada e o universo social emerge como um agregado fragmentário de indivíduos num vazio sem restrições históricas e materiais" (2002: 275). A idéia merece maior desenvolvimento. Os filosofemas trans-humanistas, mesmo quando pregam utopias coletivas, são essencialmente avessos à idéia de uma organização social, já que esta implica, de certo modo, uma limitação das possibilidades máximas de cada indivíduo.

Para ser inteiramente coerente com suas premissas, o transhumanismo deve constituir-se numa afirmação do indivíduo como artista de si mesmo; como ser que, insurgindo-se contra os tradicionais padrões culturais, sociais e cognitivos ("memes"), rompe todas as fronteiras e produz uma transvaloração de todos os valores. Mas os discursos da ciberutopia raramente buscam a coerência. São sistemas de valor que hesitam entre o excesso e a contenção, entre o revolucionário e o convencional. Desse modo, no site da Associação Mundial Transhumanista, prega-se a necessidade de se criar fóruns "onde as pessoas possam debater racionalmente sobre o que precisa ser feito, e uma ordem social na qual decisões responsáveis possam ser implementadas" 3 . Curiosamente, também se afirma que o movimento transhumanista "abarca muitos princípios do humanismo moderno" ${ }^{\prime}$.

Calabrese fala no excesso contemporâneo como um princípio endógeno. Em outras palavras, trata-se de um excesso que trabalha do interior do próprio sistema, estendendo seus limites em lugar de rompê-los. $\mathrm{Na}$ verdade, uma característica tradicional dos sistemas sociais é a capacidade de integrar o excesso, "tornando substancialmente normal uma aparência excessiva" (Calabrese, 1988: 79). No âmbito da cultura contemporânea, os discursos da ciberutopia podem parecer transgressores e libertários, mas trata-se de uma subversão domesticada, controlada. Como explica Terranova, o entusiasmo utópico da filosofia pós-humanista é contrabalançado por temores distópicos $^{5}$ e, poderíamos acrescentar, valores conservadores. Como demonstra Terranova em sua análise dos discursos ciberutopistas, a associação entre idéias como televisãofeminilidade-estupidez é "parte de uma significante estratégia de oposições e analogias definindo a identidade tanto das novas tecnologias 'interativas' (como opostas à televisão) quanto de seus usuários 'ativos' (como opostos à passividade feminina)" (2002: 272).

Além dos procedimentos propriamente retóricos, é interessante também falar no modo de apresentação dos discursos da cibercultura. Muitos se apresentam na forma de manifestos. É o caso do célebre texto de Haraway, por exemplo. O manifesto constituía a forma discursiva por excelência das vanguardas. Futurismo, dadaísmo, cubismo, surrealismo: todos tiveram seus manifestos expressando o desejo do rompimento 
absoluto com o passado; o estabelecimento de uma nova hybris em busca de realizações espetaculares e inéditas. Em tempos pósmodernistas, porém, essa retomada da forma-manifesto se esvazia de sentido. Como diz Eduardo Subirats, em relação ao esgotamento das vanguardas, "suas atitudes converteram-se há muito em espetáculo ritualizado, em gesto representativo e narcisista, em afirmação vazia de poder" (1986: 11). Os manifestos da cibercultura são sintoma dessa derrocada das utopias modernistas, que agora reeditam antigos sonhos tecnológicos sob roupagens aparentemente novas. A retórica do manifesto do movimento FutureCulture é semelhante à de seus correligionários:

"Assim como uma tecnocracia é um governo dirigido por cientistas ou aqueles que criam a tecnologia, a tecnocultura é uma cultura alimentada pela tecnologia. A América é tecnocultura. Nós estaríamos perdidos sem nossas televisões ou carros, nossos computadores ou telefones. FutureCulture é, portanto, uma forma de decifrar como o amanhã irá parecer em uma tecnocultura ${ }^{6 \prime}$.

A tecnocultura se apresenta como uma forma híbrida, um cenário cultural no qual a tecnologia está tão inextricavelmente ligada à vida cotidiana que é dela inseparável. É preciso assinalar, porém, que toda cultura já é desde sempre tecnológica. Como diz Erik Davis, "a cultura é tecnocultura" (1998: 10). Podemos, contudo, admitir o uso do conceito para expressar a individualidade do momento histórico que agora se apresenta. Se a cultura sempre foi tecnológica, é apenas no contexto da "tecnocultura" que ela passa a se pensar explicitamente como tal e tomar como objeto de reflexão toda a extensão dos problemas implicados na conjunção homem-máquina. Para Geoff Waite, que, como Sfez e Terranova, crê na antecipação nietzschiana do tema do pós-humano, a tecnocultura se caracteriza pela constituição de um self ciborgue, habitante de uma paisagem cultural híbrida, resultado da mescla de elementos da cultura popular ("junk culture"), de fragmentos filosóficos (especialmente dos filosofemas nietzschianos) e do culto ao tecnológico. E nessa paisagem filosófica passeiam ainda os tradicionais mitos de modernização das primeiras utopias tecnológicas. Em última instância, como afirma Jonathan Crary, nos encontramos em "mais um daqueles momentos recorrentes no século $X X$ em que uma das máscaras do fracasso e da paralisia do político é a entusiasmada afirmação da força transformadora e da centralidade cultural da inovação tecnológica" (apud Waite, 1996: 16). Uma forma não de pensamento revolucionário, portanto, mas de conformismo infantil que oculta a derrocada do projeto moderno.

Aliás, é interessante observar a série de metáforas infantis com que se inicia o manifesto FutureCulture. Em uma paisagem bucólica, uma criança sopra bolhas de sabão e, de repente, pára para observar a beleza de uma bolha em particular. Nessa observação descobre todo um mundo novo e fascinante. As bolhas se combinam, estouram, adquirem formas exóticas, se aproximam e se afastam. Tudo para metaforizar o processo do diálogo e intercâmbio entre as várias facções e elementos de uma cultura. As bolhas são "subculturas" (como, por exemplo, a cultura cyberpunk), que nascem, se desenvolvem, morrem, se afastam e se reaproximam no horizonte mais amplo desse grande environment que é a Cultura. A metáfora nos transporta para um paraíso originário, para um estado de inocência e pureza fora do tempo e do espaço. Um mundo adâmico das conciliações, anterior à ruptura da Queda, e ao qual a tecnologia agora poderia nos devolver. Vale a pena reproduzir um trecho da passagem:

"Desse modo, como se pode ver, as subculturas se combinam em culturas ou subculturas mais amplas (é tudo relativo), as subculturas podem se autodestruir, podem evoluir ou meta- 
morfosear-se, podem divergir para diferentes direções. Mas em qualquer dos casos, sempre há bolhas, pois nós, como aldeia global, somos como o menino de cinco anos - entrincheirado no mundo das bolhas, olhando-as com um olhar de admiração ${ }^{7 \prime \prime}$.

O imaginário de excesso e transgressão da cibercultura revela-se, assim, como conservadorismo político e mitologia religiosa. Esse imaginário envolve, como tenho procurado demonstrar ${ }^{8}$, uma deificação da tecnologia como forma de obtenção da transcendência humana. Misticismo e ciência são termos intercambiáveis nessa equação, segundo um dos princípios do Manifesto Pós-Humanista: "O pós-humano está inteiramente aberto a idéias de 'paranormalidade', 'imaterialidade', 'sobrenatu$\mathrm{ral}^{\prime}$ e 'oculto'. O pós-humano não aceita que a fé em métodos científicos seja superior à fé em outros sistemas de crença" ${ }^{\prime \prime}$. Temos, assim, efetivamente, mais um exemplo da transgressão de limites tão própria do gosto contemporâneo. Contudo, mais que atitude inovadora ou revolucionária, essa aproximação entre tecnologia e religiosidade representa um retorno a paradigmas anteriores, a uma visão de mundo pré-moderna, na qual os dois domínios apresentavam-se intimamente conectados ${ }^{10}$.

Há um outro aspecto do tema do excesso na cibercultura que, por sua centralidade, merece nossa atenção. Falo do tema da informação, da idéia de information overload ou data smog, como o qualifica David Shenk (1997); o excesso de informação. Diz-se que não é possível ter-se algo bom em demasia. Informação, aparentemente, é algo desejável e tradicionalmente implica as idéias de transformação, desenvolvimento e crescimento. Mais que em qualquer outra época da história, na cultura contemporânea a informação passou a ser encarada como o bem fundamental. Contudo, o tema do excesso de informação, que de fato não cessa de multiplicar-se no âmbito das redes digitais, constitui uma das principais fon- tes de distopia no imaginário cibercultural. Shenk afirma que o fenômeno da "névoa de dados" (data smog) nos atinge constantemente em nosso cotidiano na tecnocultura:

"Ele agita os momentos silenciosos e obstrui os tão necessários instantes de contemplação. Ele arruína a conversação, a literatura e mesmo o entretenimento. Ele inviabiliza o ceticismo, tornando-nos menos sofisticados como consumidores e cidadãos. Ele nos estressa (1997: 31)".

O grande pesadelo do excesso de informação é a impossibilidade de escapar dela, de encontrar um "local" da cultura que não esteja sobrecarregado de estímulos informacionais. Em Minority Report (2002), encontramos uma representação desse pesadelo na idéia de uma sociedade inteiramente controlada pela informação. Sensores eletrônicos escaneiam a retina das pessoas, submetendo-as a um constante bombardeio de propaganda dirigida em qualquer lugar por onde passem.

Katherine Hayles aponta, inteligentemente, as conexões que existem entre os temas da informação e do pós-humano. Um dos filosofemas do pós-humanismo repousa na noção da consciência como fluxo de processos informacionais. Se somos, essencialmente, padrões de informação (inclusive geneticamente falando) e se a informação se apresenta como bem imaterial, nada mais natural que desejar a eliminação dessa materialidade incômoda do corpo. Sem descartar o tema do pós-humanismo, Hayles contudo imagina a possibilidade de uma perspectiva alternativa, menos contaminada pelo mito e pelo desejo do excesso:

Meu sonho é uma versão do pós-humano que abrace as possibilidades das tecnologias da informação sem ser seduzida por fantasias de poder ilimitado e imortalidade descorporificada; que reconheça e celebre a finitude como uma condição do ser humano, e que entenda a vida humana como embebida em um mundo material 
de grande complexidade, mundo do qual dependemos para continuar sobrevivendo (1999: 5).

Mas não parece ser fácil separar a imaginação pós-humanista de seus mitos de transgressão, excesso e superação da finitude humana. A visão informacional da cultura desmaterializa a realidade e assim facilita a propagação dos mitos da digitalização corporal. Paulo Vaz observa que enquanto um dos problemas centrais da modernidade era a falta (falta de informação, de acesso à verdade), na cultura contemporânea revertemos ao problema do excesso e da rapidez (1999: 117). São esses dois elementos que situam os sujeitos contemporâneos em um ambiente destemporalizado e desmemoriado. Oferecida de forma descontextualizada, fragmentária, rápida e excessiva, a informação acaba constituindo-se em não-informação.

Chegando a este ponto, já é possível fazer uma síntese do percurso até aqui traçado e propor algumas hipóteses:

1) O excesso não é um traço constitutivo da natureza física; na realidade, o universo se caracteriza pela tendência à entropia típica de todo sistema fechado. O que o mantém em funcionamento são os processos de diferenciação e antagonismo da matéria microfísica;

2) Nada indica que qualquer forma de excesso seja positiva. Pelo contrário, a noção de excesso implica a presença de uma quantidade exagerada, em um sistema, de um determinado elemento e, portanto, uma situação de desequilíbrio. O excesso implica homogeneização e assim impede a manifestação de uma diferença criadora;

3) A antropologia clássica prega que a despesa excessiva pode ser entendida como um ritual de poder. Dessa forma, desperdiçar bens materiais, energia ou informação pode ser entendido não como uma forma de resistência aos processos de acumulação do capitalismo selvagem, mas como a ex- pressão de um desejo de poder totalitário;

4) A cultura contemporânea apresenta um gosto pelo excesso e pelo limite, mas esse gosto raramente se manifesta como forma revolucionária e transformadora do sistema. Pelo contrário, em muitas ocasiões, tal gosto se constitui em mais um mecanismo de controle e manutenção do sistema;

5) Os discursos do excesso e da transgressão na cibercultura estão carregados de mitos utópicos e fantasias distópicas, revelando as contradições internas dessa Weltanschauung. Na maioria das vezes, podem ser criticamente percebidos como expressão de uma ingenuidade infantil, que busca recuperar o vigor transgressor da modernidade, mas acaba por recair em um imaginário pré-moderno e numa visão religiosa e reconciliadora dos conflitos sociais.

É possível que o quadro aqui pintado seja considerado excessivamente sombrio. Talvez o seja, de fato, mas não tanto devido a alguma forma de pessimismo de matriz frankfurtiana. Ocorre que a prevalência dos discursos afirmativos no horizonte da cibercultura é tão grande que qualquer forma de perspectiva alternativa deve ser formulada com a máxima acidez da visão crítica. $\mathrm{O}$ entusiasmo pelas novas tecnologias, do qual muitos de nós - inclusive aquele que escreve estas linhas - compartilhamos, talvez represente, num obscuro recôndito de nosso inconsciente cultural, a expressão de um desejo de salvação tecnológica. Em um mundo onde o sentido se evaporou, onde a sensação se anestesiou, onde o percurso histórico estacionou, nada mais natural que almejar o prazer ciborgue da dissolução de fronteiras. Mas é a fronteira última da nossa finitude que pode também nos resguardar contra as formas mais agudas da insanidade.

\section{Notas}

1 Este trabalho foi originalmente apresentado no XXVI Congresso Brasileiro de Ciências da Comunicação, realizado 
em Belo Horizonte, em setembro de 2003.

2 Disponível em http://wwww.extropy.orgaboutindex.html. Memético (memetic) é um termo cunhado pelo biólogo Richard Dawkins e que fez fortuna no universo da cibercultura. Um meme indica aquela espécie de comportamento ou hábito cognitivo que segue padrões fortemente estabelecidos e que se repetem, de modo similar ao que sucede nos processos de replicação genética.

3 Disponível em http://www.transhumanism.org decla-ration. $\mathrm{htm}$

4 Idem.

5 Como no caso do manifesto extropiano, os princípios da Associação Mundial Transhumanista também apresentam os possiveis perigos do desenvolvimento tecnológico: "Por outro lado, também seria trágico se a vida inteligente fosse extinta por causa de algum desastre ou guerra envolvendo tecnologias avançadas" - também em http://wwww.transhumanism.org/declaration.htm. 0 imaginário da literatura cyberpunk e da ficção científica é pródigo em fantasias apocalípticas e distópicas.

6 Disponível em http:project.cyberpunk.ruidbfuture_culture_manifesto.html.

7 Disponível em http://project.cyberpunk.ru/idb/future_culture_ manifesto.html.

8 Ver, por exemplo, meu artigo "Tecnognose: Tecnologias do Virtual, Identidade e Imaginação Espiritual", in Revista Famecos $n^{0} 18$. Porto Alegre: Famecos/PUCRS (agosto 2002).

9 Disponível em http://www.stem-arts.com/Posthum/scihtm

10 A esse respeito, ver Noble, David. The Religion of Technology: the Divinity of Man and the Spirit of Invention. London: Penguin, 1999.

\section{Referências}

BATAILLE, Georges. A Parte Maldita (Precedida de "A Noção de Despesa"). Rio de Janeiro: Imago, 1975.

CALABRESE, Omar. A Idade Neobarroca. Lisboa: Edições 70, 1988.
DAVIS, Erik. Techgnosis: Myth, Magic + Mysticism in the Age of Information. New York: Three Rivers Press, 1998.

HARAWAY, Donna. "Manifesto Ciborgue", in DA SILVA, Tomaz Tadeo (org.). Antropologia do Ciborgue. Belo Horizonte: Autêntica, 2000.

HAYLES, Katherine. How we Became Post-Human: Virtual Bodies in Cybernetics, Literature and Informatics. Chicago: The University of Chicago Press, 1999.

LEMOS, André. Cibercultura: Tecnologia e Vida Social na Cultura Contemporânea. Porto Alegre: Sulina, 2002.

LUPASCO, Stéphane. La Tragédie de l'Énergie. Paris: Casterman, 1970.

.Logique et Contradiction. Paris: PUF, 1947.

SFEZ, Lucien. A Saúde Perfeita: Crítica de uma Nova Utopia. São Paulo: Loyola, 1996.

SHENK, David. Data Smog: Surviving the Information Glut. New York: Harper Edge, 1997.

SUBIRATS, Eduardo. Da Vanguarda ao Pós-Moderno. São Paulo: Nobel, 1986.

TERRANOVA, Tiziana. "Post-Humam Unbounded: Artificial Evolution and High-Tech Subcultures", in BELL, David \& KENNEDY, Barbara (orgs.). The Cybercultures Reader. London: Routledge, 2002.

VAZ, Paulo. "Agentes na Rede", in Lugar Comum, n 7. Rio de Janeiro: Nepcom/UFRJ (janeiro-abril 1999).

WAITE, Geoff. Nietzsche's Corps/e: Aesthetics, Politics, Prophecy, or, the Spectacular Technoculture of Everyday Life. Durham: Duke University Press, 1996. 